Abstract

\title{
Integrating Gene Editing Techniques into Modern Cereal Breeding ${ }^{+}$
}

\author{
Ian Godwin *, Karen Massel and Guoquan Liu \\ Centre for Crop Science, QAAFI, The University of Queensland, Brisbane, QLD 4072, Australia; \\ karen.massel@uq.net.au (K.M.); g.liu2@uq.edu.au (G.L.) \\ * Correspondence: i.godwin@uq.edu.au \\ + Presented at the third International Tropical Agriculture Conference (TROPAG 2019), Brisbane, Australia, \\ 11-13 November 2019.
}

Published: 9 April 2020

\begin{abstract}
New breeding technologies are revolutionizing plant and animal improvement programs worldwide. One of these transformative technologies is the application of gene editing, most commonly performed with CRISPR/Cas9. Gene editing allows for genes to be precisely knocked out. As a result, it can create different proteins, can make gene-express at different levels in different tissues or at developmental stages, all of which can confer novel trait combinations. Australian regulatory authorities have recently de-regulated the most simple class of edits (the Site Directed Nuclease-1 or SDN-1 edits). Plants and animals containing such edits can now be freely grown in the field with no restrictions, and hence can be used in normal plant and animal breeding programs. Similar rulings in the United States, Canada, Japan, Argentina and Brazil mean that gene-edited crops are already entering the market. We are now using CRISPR/Cas9 to edit genes in sorghum and barley, including grain quality traits, disease resistance, and yield components and developmental traits. Using examples of recent work in sorghum, barley and rice, we can explore the ways in which gene-edited plants can be integrated into inbred and hybrid plant breeding programs.
\end{abstract}

Keywords: gene editing; CRISPR/Cas9; cereal breeding

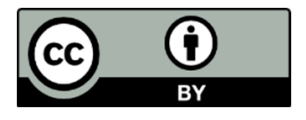

(C) 2020 by the authors. Licensee MDPI, Basel, Switzerland. This article is an open access article distributed under the terms and conditions of the Creative Commons Attribution (CC BY) license (http://creativecommons.org/licenses/by/4.0/). 